METALLURGY AND FOUNDRY ENGINEERING - Vol. 34, 2008, No. 1

\author{
Andrzej Czarski*
}

\title{
ASSESSMENT OF STATISTICAL STABILITY OF STEEL STRIP HOT-ROLLING PROCESS
}

\section{INTRODUCTION}

Quality is a challenge that must be taken up by producers. A formal requirement of quality are among others ISO 9000 standards and specific branch requirements e.g. ISO/TS 16949 standard relating to the automotive industry. The verified and efficient method of achievement of demanded quality (within time shorter than competitors!) is the organizational culture Six Sigma [1-7].

There are plenty of different verified quality tools such as: team work methods (e.g. brainstorming, quality circles), problem solving methods (e.g. flow diagram, decisions diagram, cause-and-effect diagram) and finally statistical techniques [1-3, 8].

In practical approach statistical methods in quality management are first of all: statistical process control (SPC), measurement system analysis (MSA),statistical acceptance plans and statistical methods in process improvement (ANOVA, DOE etc.) [8-13].

Among the statistical methods mentioned above nowadays the most significant place takes the statistical process control (SPC). One of the fundamental tasks of SPC is current (on-line) monitoring of a process by means of control charts. They are first of all Shewhart's control charts [9-14].

\section{CONTROL CHARTS}

\subsection{Variability and stability of process}

Variability is an inseparable feature of each process meant widely as a transformation inputs into outputs. In SPC there is a following division of causes generating a process variability $[9,12,13]$ :

* Ph.D., Faculty of Metals Engineering and Industrial Computer Science, AGH University of Science and Technology, Cracow, Poland; czarski@uci.agh.edu.pl 
- Chance causes of variation (random cause, unpredictable causes); it is always the same, stable configuration of chance causes present in the process (so-called noise). If the process is caused by the same, stable configuration of causes generating variability, it is stable in statistical meaning. In other words the process is predictable.

- Assignable causes (determinable causes); they are causes that appear in a process in a way impossible to predict (defect of raw material, operator's negligence, damage of a tool, ...). At presence of this causes the process is said to be out of control, in other words the process becomes unpredictable.

The presented division has a basic meaning in assessment of process performance regarding a variability. For current (on-line) monitoring of a process for the sake of variability a technique of control charts is applied. One of the fundamental tasks of each control chart is separation "signals" from "noises". By "noise" we mean a constant system of factors generating variability, and "signals" are consequences of assignable causes. If there is a signal identified in a control chart, it shall be identified and interpreted. Identification and interpretation of "signals" is the most interesting, difficult and important task in scope of control chart application. We can not speak about SPC without processing information coming from a control chart into concrete technician and technological actions.

A control chart is only the way of achievement of information about the process. The achieved information must be followed by concrete actions. Without such actions a control chart will not be a tool for process improvement.

\subsection{Shewhart's control charts}

For the sake of construction simplicity, easy interpretation and sufficiently good sensitivity (i.e. capability for change detection in a process) Shewhart's control charts are used the most often [9-11, 14].

To monitor the process regarding measurable parameters we use the following charts:

- Chart of average value $\bar{x}$ and range $\mathrm{R} ; \bar{x}$-R chart

- Chart of average value $\bar{x}$ and standard deviation $\mathrm{s} ; \bar{x}$-s chart

- Chart of median $\tilde{x}$ and range $\mathrm{R} ; \tilde{x}$ - $\mathrm{R}$ chart

- Chart of individual observations $x$ and moving range MR; $x-M R$ chart

To monitor the process regarding attributes (i.e. alternative assessment e.g. conforming/ not conforming, defect/ no defect) we use the following charts:

- Chart of fraction of nonconforming units; $p$ chart

- Chart of number of nonconforming units; np chart

- Chart of number of nonconformities; c chart

- Chart of number of nonconformities per unit; $u$ chart

All mentioned control charts can be constructed with one of two methods [9-11, 14]. The first method is so-called a stabilization method (no standard given method). In this method the chart is constructed on the basis of preliminary data coming from the process. Such a chart serves to control the process regarding stability; it is a "pattern" of a stable process to which we refer the further behavior of the process. 
The second method is so-called a designing method (standard given method). The basis of this method are assumed requirements relating to the process behavior (e.g. through expected capability indices $\mathrm{Cp}, \mathrm{Cpk}$ ). Such a chart serves to estimate whether the process meets requirements determined, defined in designing. The preferable way of control chart construction is the stabilization method.

The special control chart is a chart of single observations and moving range. It is used when there is no possibility to complete a sample - the sample in case of this chart is a single value. Such a chart is suitable to monitor the process regarding technological parameters (pressure, temperature etc.). It is worth noticing that a single value can be and should be understood widely; it may be e.g. an arithmetical average of many measurements that indicates for example a diameter in this place.

\section{EXPERIMENTAL PROCEDURE}

\subsection{Aim, material, results of experiment}

The aim of investigations was to assess stability of technological process of hot-rolling of steel strip (steel DC03) $-3 \mathrm{~mm}$ of nominal thickness and $1430 \mathrm{~mm}$ of wideness. There were available the results of thickness measurements made with an X-ray thickness gauge as well as measurements of convexity and wedge shape made with a profile measurement gauge on coils from consecutive melts. Data for analysis came from the laboratory of mechanical and geometrical properties testing.

In the framework of performed analysis the control charts of individual observations and moving range (x-MR) have been constructed and - relating to the thickness of strip the assessment of short-term capability $\mathrm{Cp}$, Cpk and long-term capability Pp, Ppk indices has been made. The methodic and interpretation of the mentioned capability indices have been in details presented in the previous work [12].

The results of investigations are shown in Figures 1-3 and in Tables 1, 2.
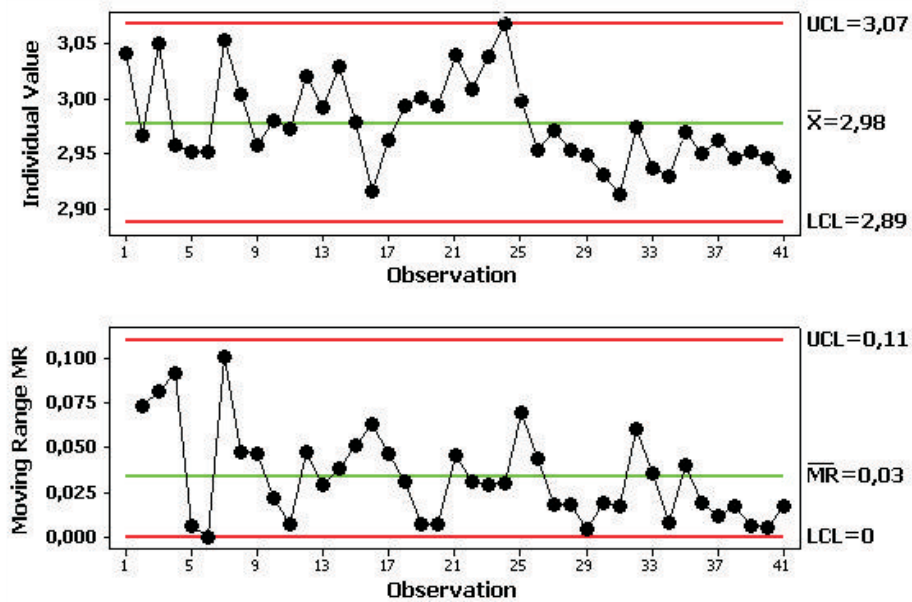

Fig. 1. Thickness - chart of individual observation $x$ and moving range MR ( $x$-MR chart) 

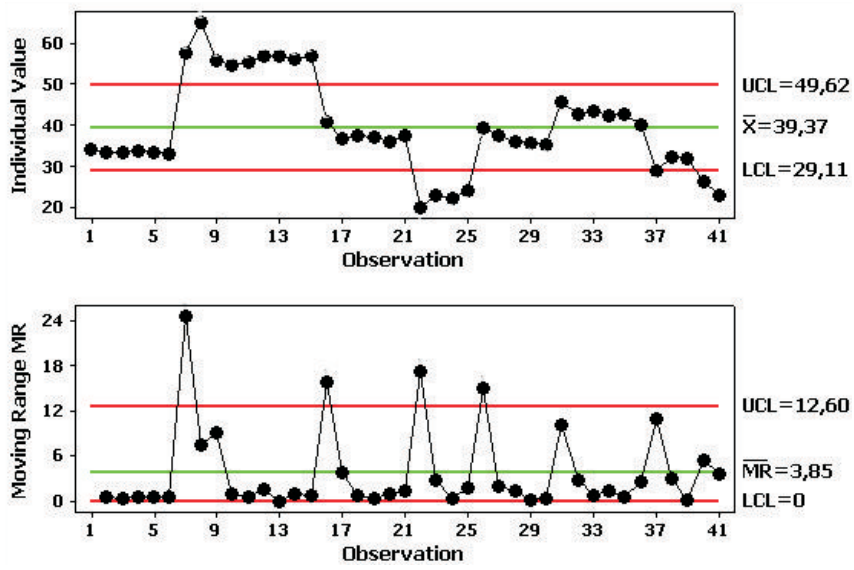

Fig. 2. Convexity - chart of individual observation $x$ and moving range $M R(x-M R$ chart)
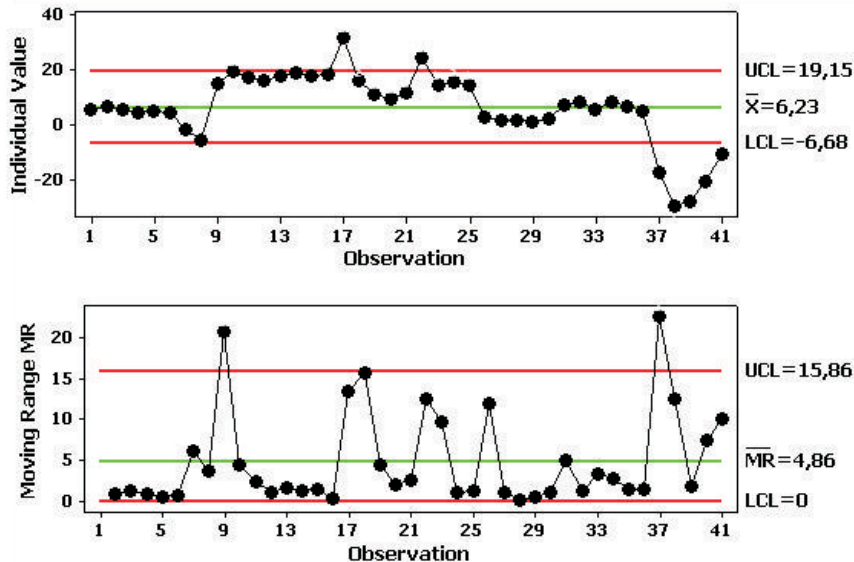

Fig. 3. Wedge shape - chart of individual observation $x$ and moving range MR (x-MR chart)

Table 1. Charts of individual observation $x$ and moving range MR (x-MR chart) - central lines, control lines

\begin{tabular}{|c|c|c|c|c|c|c||}
\hline \multirow{2}{*}{ Parameter } & \multicolumn{5}{|c|}{ x chart } & \multicolumn{3}{c||}{ MR chart } \\
\cline { 2 - 7 } & CL & UCL & LCL & CL & UCL & LCL \\
\hline Thickness & 2.98 & 3.07 & 2.89 & 0.03 & 0.11 & 0 \\
\hline Convexity & 39.37 & 49.62 & 29.11 & 3.85 & 12.60 & 0 \\
\hline Wedge shape & 6.23 & 19.15 & -6.68 & 4.86 & 15.86 & 0 \\
\hline \begin{tabular}{l} 
Explanations: \\
\hline $\begin{array}{l}\text { CL } \\
\text { UCL, LCL }\end{array}$
\end{tabular} \\
upper and lower control limit, respectively \\
\hline
\end{tabular}


Table 2. Thickness - short term capability Cp, Cpk and long-term capability Pp, Ppk

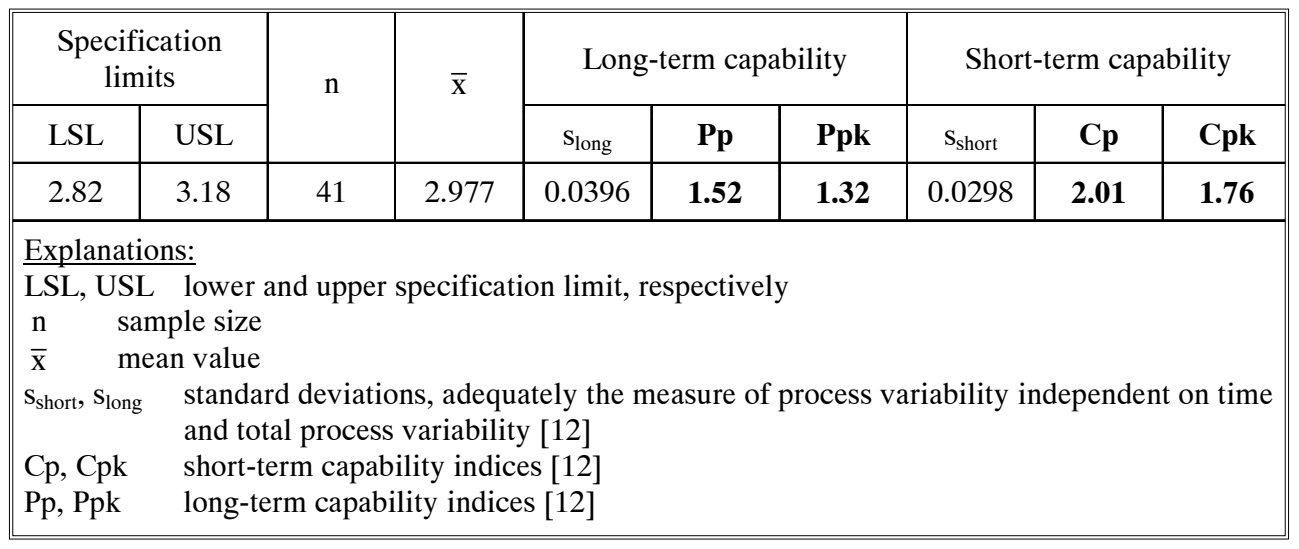

\subsection{Discussion of results}

For the sake of analyzed parameters the process behavior presents itself as follows.

Thickness. In the control chart of individual values and moving range $\mathrm{x}-\mathrm{MR}$ (Fig. 1, Tab. 1) there are no points outside control limits (signals), however starting from the observation no. 33 appears very distinct 9-point "run" speaking the most likely for moving the process in the direction of less values. Therefore, in statistical meaning, the process is not stable relating to its position. No stability of the process means the presence of so-called a component of variability dependent on time (in the analyzed process "no. of melt" is responsible for the presence of this component). The conclusion about the lack of stability is confirmed also by results of the assessment of short-term capability $\mathrm{Cp}, \mathrm{Cpk}$ and long-term capability Pp, Ppk, viz. Pp $<$ Cp, Ppk $<$ Cpk (Tab. 2).

More detailed analysis of these indices indicates that impact of component of time variability is not so significant and, in spite of presence of this component, the process meets client's expectations (Ppk > 1.3).

Convexity, wedge shape. Configurations of points in charts of single observations and movable range $\mathrm{x}$-MR (Figs 2, 3, Tab. 1) have the same character and speak for existing of very strong number-of-melt-dependence. In other words, in case of both the parameters analyzed there is a very distinct and strong component of variability dependent on time (from the melt to the melt).

The discussion presented hereby concerns only the aspect of statistical analysis of data. It is worth adding that in the performed overall analysis conclusions concerning the process behavior relating to the analyzed parameters coming from the made statistical analysis were the inputs for the analysis of technological aspects and basis of actions for process improvement.

\section{SUMMARY}

Analysis of process stability using control charts as well as assessment of process capability indices $\mathrm{Cp}, \mathrm{Cpk}, \mathrm{Pp}$, Ppk delivers very important information in subject of the process run and its potential relating to client's expectations. Results of such analysis can be 
both the document of meeting specified quality requirements for Client and information for the process holder about the present condition of the process and the potential for its improvement.

\section{Acknowledgments}

The financial support from the Polish Ministry of Science and Higher Education, contract AGH no.10.10.110.797 is gratefully acknowledged.

\section{REFERENCES}

[1] Lock D.: Guide of Quality Management, PWN, Warsaw, 2002 (in Polish)

[2] Pyzdek T:: Quality Engineering Handbook, Second Edition, Marcel Dekker, Inc., 2003

[3] Hamrol A.: Quality Management with applications, PWN, Warsaw, 2005 (in Polish).

[4] Pande P.S., Neuman R.P., Cavanagh R.R.: Six Sigma. How GE, Motorola and Other Top Companies are Honning Their Performance, KE Liber S.C., 2000 (in Polish)

[5] Pande P., Holpp L.: What is Six Sigma, First Edition, McGraw-Hill, 2001.

[6] Stamatis D.H.: Six Sigma and Beyond. Foundations of Excellent Performance. Ed. CRC Press, 2001

[7] Rath\&Strong's Six Sigma leadership handbook, Edited by Thomas Bertels, John Wiley\&Sons, Inc., 2003

[8] Glossary and Tables for Statistical Quality Control, Fourth Edition, ASQ Statistics Division, ASQ Quality Press, 2004

[9] Montgomery D.C.: Introduction to Statistical Quality Control, Fourth Edition, John Wiley\&Sons, Inc., 2000

[10] Joglekar A.M.: Statistical Methods for Six Sigma. In R\&D and Manufacturing, John Wiley\&Sons, Inc., 2003

[11] Breyfogle III F.W.: Implementing Six Sigma. Smarter Solutions Using Statistical Methods, Second Edition, John Wiley\&Sons, Inc., 2003

[12] Czarski A.: Capability Process Assessment in Six Sigma Approach, Metallurgy and Foundry Engineering, 33 (2007), $105 \div 111$

[13] Czarski A., Satora K., Matusiewicz P.: Statistical Methods in Quality Management - Process Capability Analysis, Metallurgy and Foundry Engineering, 33 (2007), 121 $\div 128$

[14] Dudek-Burlikowska M.: Quality Estimation of Process with Usage Control Chards Type X-R and Quality Capability of Process Cp, Cpk, Proceedings of the $13^{\text {th }}$ International Scientifics Conference AMME'05, Gliwice-Wisła, Poland, May 2005, 211 216

Received

October 2008 